\title{
倩第 \\ Os vínculos entre condições de trabalho e saúde mental
}

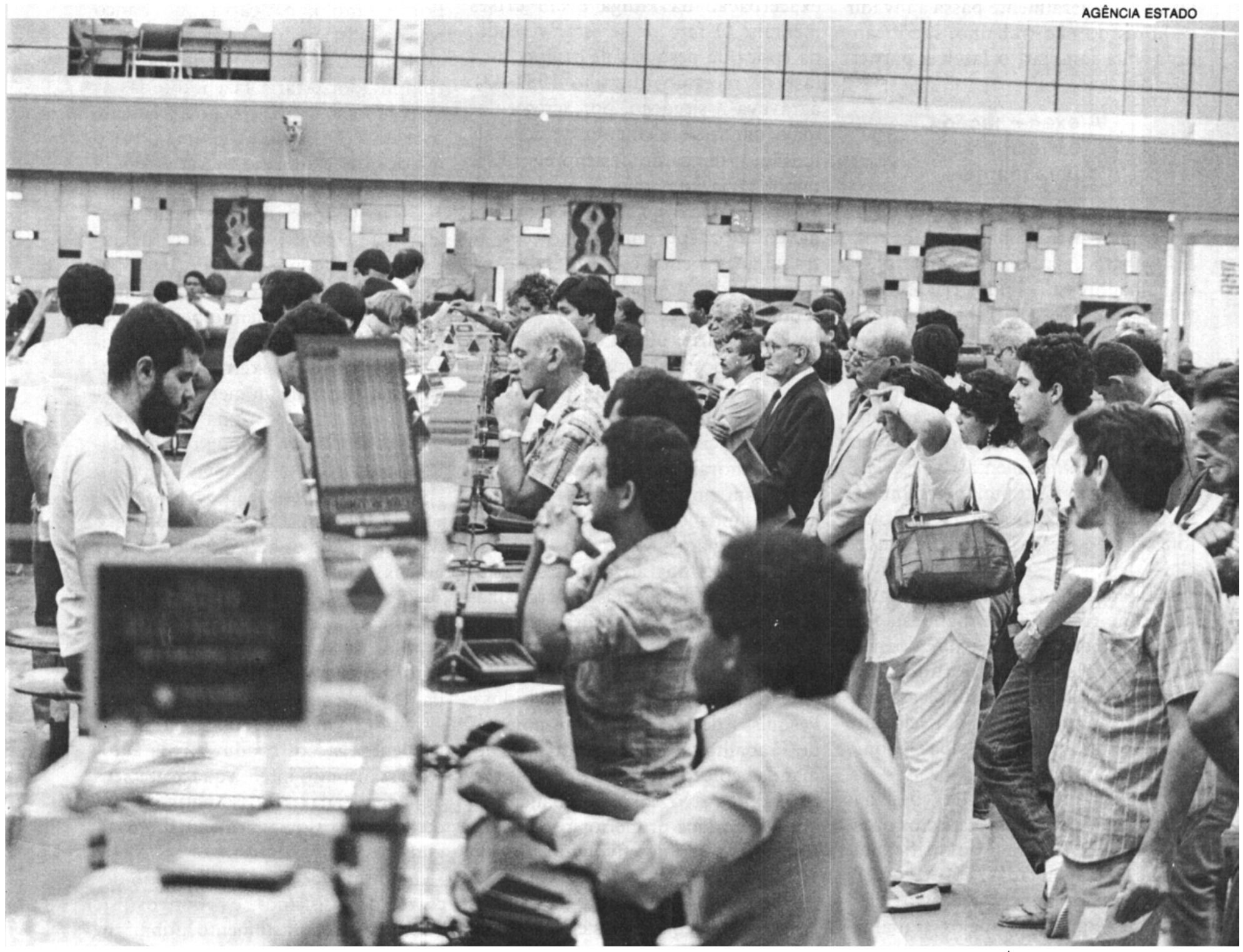

Edith Seligmanw Silva, psiquiatra, professora do Departamento de $\mathrm{Me}$ dicina Preventiva da Universidade de Säo Paulo e membro do grupo de técricos e assessores do DIESAT, vem desenvolvendo sistematicamente pesquisas e estudos sobre a questão da saúde mental no trabalho; por essa razão, colhemos o seguinte depoimento:
"Constatamos, de maneira muito nítida, $\mathrm{cm}$ nossas pesquisas o que já havia sido estudado em outros países: a vinculação entre condiçōes organizacionais e ambientais do trabalho, de um lado, e os níveis de saúde mental, de outro. Vale lembrar que, fora do âmbito 'psi', no Brasil, vários cientistas sociais já haviam detectado essa correlação, estudando o cotidia- no de diferentes categorias de trabathadores. Por exemplo, Maria Cecilia Minayo e Yone de Souza Grossi pesquisaram, respectivamente, os trabathadores de extração de ferro e os de extração de ouro. Em seus estudos, revelaram muito do sofrimento mental destes trabalhadores relacionado à dominação vivenciada, dentro de processos de trabalho, e marcado por 
uma exploração inaudita, como ainda existem em muitos lugares do Brasil. A necessidade de sustento para si e para suas famílias faz as pessoas suportarem situações em que, além de muitas vezes viverem em constante situação de risco de acidente, elas são feridas em sua dignidade. Há situaçōes em que as necessidades mais básicas - inclusive as fisiológicas - são desrespeitadas e submetidas a disciplinas rígidas. $O$ cansaço chega à cronificação e geralmente passa a invadir as horas do não-trabalho, sacrificando a vida familiar, o lazer, a participação social.

\section{A exacerbaç̃o da fadiga crises mentais}

A primeira pesquisa, na qual participei junto a trabalhadores, foi feita em Cubatão, na Baixada Santista. Os trabalhadores das indústrias de base vivem condições de trabalho, muitas vezes, potencialmente degradantes, associadas a condições gerais de vida muito difíceis. Mesmo assim, manifestam resistências admiráveis contra estas condiçōes, revelando assim sua vitalidade e saúde mental. Apesar disso, a situação de trabalho geralmente se torna adoecedora, a médio ou a longo prazo, desgastando essa saúde.

Realizamos estudos de casos de trabalhadores que haviam tido afastamento do trabalho por manifestações de distúrbio mental ou por doenças psicossomáticas. Esses estudos evidenciaram, de fato, profunda associação entre o processo de adoecimento e o trabalho destas pessoas. Como ocorre essa associação? De várias maneiras, por inúmeras interaçōes, nas quais participam tanto aspectos organizacionais (ritmos intensificados, jornadas prolongadas, insuficiência de pausas, controle coercitivo e permanente sofrimento pelos trabalhadores, além de outras características) quanto aspectos ambientais e as próprias condições de vida.

Verificamos que várias crises mentais agudas haviam sido desencadeadas por grandes aumentos de jornada de trabalho, fosse por dobras de turno (com 16 horas de trabalho), fosse através do aumento das horas extras. Nessas indústrias de base, especialmente no trabalho siderúrgico e no setor petroquímico, a maioria dos operários trabalha em regime de turnos alternados, ou de revezamento, o que por si somente se constitui em um importante fator de risco, tanto para a saúde geral quanto para a psicossocial. Então, quando estes trabalhadores de turnos de revezamento eram submetidos a exigências de maiores jornadas e de intensificação de ritmo de produção, como acontecia na siderúrgica, essa sobrecarga resultava em exacerbação da fadiga e em crises mentais. $\mathbf{O}$ fato de se estar vivendo, na época da pesquisa de campo, uma fase de recessão (durante 1981-83), agravava a situação, por acrescentar mais um forte elemento gerador de tensão: o temor do desemprego. Esse temor fazia com que as pessoas elevassem ao máximo seus esforços para agüentar as péssimas condiçōes de trabalho existentes em seus empregos. Desse modo, a situação também desembocava, para muitos, em hipertensão, enfarte, úlcera etc.

Não é possível estudar psicopatologia do trabalho sem escutar os depoimentos dos trabalhadores sobre suas vivências relacionadas ao cotidiano laboral. Infelizmente, só agora se iniciam em nosso país - e mesmo assim, ainda em poucas Faculdades de Psicologia ou Medicina - aulas e estudos referidos ao assunto. Muito antes que as academias, os trabalhadores percebem as relações entre trabalho e sofrimento mental. Tanto que os estudos pioneiros do DIESAT (Departamento Intersindical de Estudos e Pesquisas de Saúde e dos Ambientes de Trabalho) surgiram a partir de demandas colocadas pelos próprios trabalhadores. No caso dos bancários, que foi um dos primeiros projetos de pesquisa a ser desenvolvido ali, em 1984, foi muito interessante o seu começo com um grupo de estudos composto por bancários e técnicos do DIESAT.

A idéia de desenvolver uma pesquisa sobre condiçōes de trabalho e saúde mental dos bancários foi amadurecendo e foi solicitada de maneira explícita pelo Sindicato dos Bancários de Campinas e pela Federação dos Bancários de São Paulo, Mato Grosso do Sul e Paraná. Foi elaborado um projeto por uma equipe multidisciplinat do DIESAT (psicóloga Leny Sato, socióloga Agda Delia, médico Francisco Lacaz e eu), conjuntamente com os bancários. Todo o processo desta pesquisa também continuou sendo realizado e avaliadode maneiraconjunta.

\section{As mudanças na organizaçōo do trabalho}

O problema inicial levantado pelos bancários estava relacionado com a implantação da computadorização. Por exemplo, o 'caixa' do banco passou a trabalhar com o sistema 'one-line', em que aparentemente o computador estaria fazendo todas as operaçōessozinho, masconcretamente passou a haver um volume muito maior e diversificado de tarefas para - 'caixa' . $O$ banco passou a receber mais serviços: mensalidades de escola, pagamento de impostos, carnês diferentes, enfim uma série de prestação de serviços que não se faziam antes. Estes serviços possuem especificaçōes diferentes para cada um deles e exigem do 'caixa' o exercício de memorizar um grande número de instruções, resultando numa sobrecarga mental. Por outro lado, a responsabilidade do 'caixa' aumentou muito com essa diversificação de serviços.

Em termos gerais, a administração determina que os bancários devem ser gentis com os clientes e que estes "sempre têm razão'. Como aumentou a carga de trabalho, aumentaram as filas de usuários e a impaciência destes também aumentou, levando os bancários a suportar uma grande carga de agressividade dos clientes, diariamente. Isto os conduz a uma autorepressão muito intensa que acaba sendo canalizada psicossomaticamente ou mesmo psiquiatricamente, em alguns casos.

Num grande banco estatal, no decorrer de dois anos, os motivos psiquiátricos de afastamento atingiram um nível de $14,06 \%$ de todos os afastamentos por doença. $O$ diagnóstico psiquiátrico mais freqüentenessemesmo banco foi o de depressão. Estudos de casos em bancários que haviam recebido esse diagnóstico demonstraram que a depressão havia se constituído reativamente a situaçōes vinculadas estreitamente ao trabalho: vivência de desqualificação, frustração de projetos de carreira e de vida, esva- 
ziamento de motivaçāo, sensação de aprisionamento dentro de um cotidiano entediante.

Outros diagnósticos treqüentes foram obesidade e hipertensão arterial. Estas patologias, cujos componentes psíquicos são bem conhecidos, também se ligam, muitas vezes, às tensōes e frustraçōes do trabalho. Por outro lado, o próprio sedentarismo do trabalho bancário também contribui, evidentemente, para a obesidade e problemas cárdio-circulatórios.

Quanto à automaçāo bancária, verificou-se, basicamente, que não era, propriamente, a maneira pela qual o trabalho estava sendo organizado nos sistemas computadorizados. Por exemplo, no caso das digitadoras, o que determina grande tensão e nervosismo nelas não é tanto a tarefa em si, mas a forma pela qual eram obrigadas a trabalhar. Tinham que dar uma elevada produção - avaliada em termos de números de toques - e que deviam aceitar situaçōes de disciplina extremamente rígida. Basta dizer que, em um dos bancos, as digitadoras eram proibidas de levantar mesmo para ir beber água, havendo severo controle dos minutos que passavam no banheiro. As perturbaçōes de sono e grande irritabilidade foram referidas também por digitadoras de outras empresas, que foram alvo de pesquisa posterior.

Os bancários queixavam também que as exigências de trabalho limitavam a sua participação na vida familiar e na vida social, em geral. Além disso, notou-se que quem tivesse se submetido a algum tratamento psiquiátrico passava a ter uma rotulação de 'pessoa problemática' dentro do serviço e sofria uma discriminação que, geralmente, se expressava por um aumento de exigência de produção, passando estas pessoas a serem mais exploradas do que as outras.

\section{Na negociação com a empresa}

Em 1985, o DIESAT foi procurado pelo Sindicato dos Metroviários de São Paulo. A equipe de técnicos do DIESAT, junto com representantes das várias escalas de horário e de linhas do metrô, desenvolveu uma nova pesquisa. Sempre desenvolvemos a

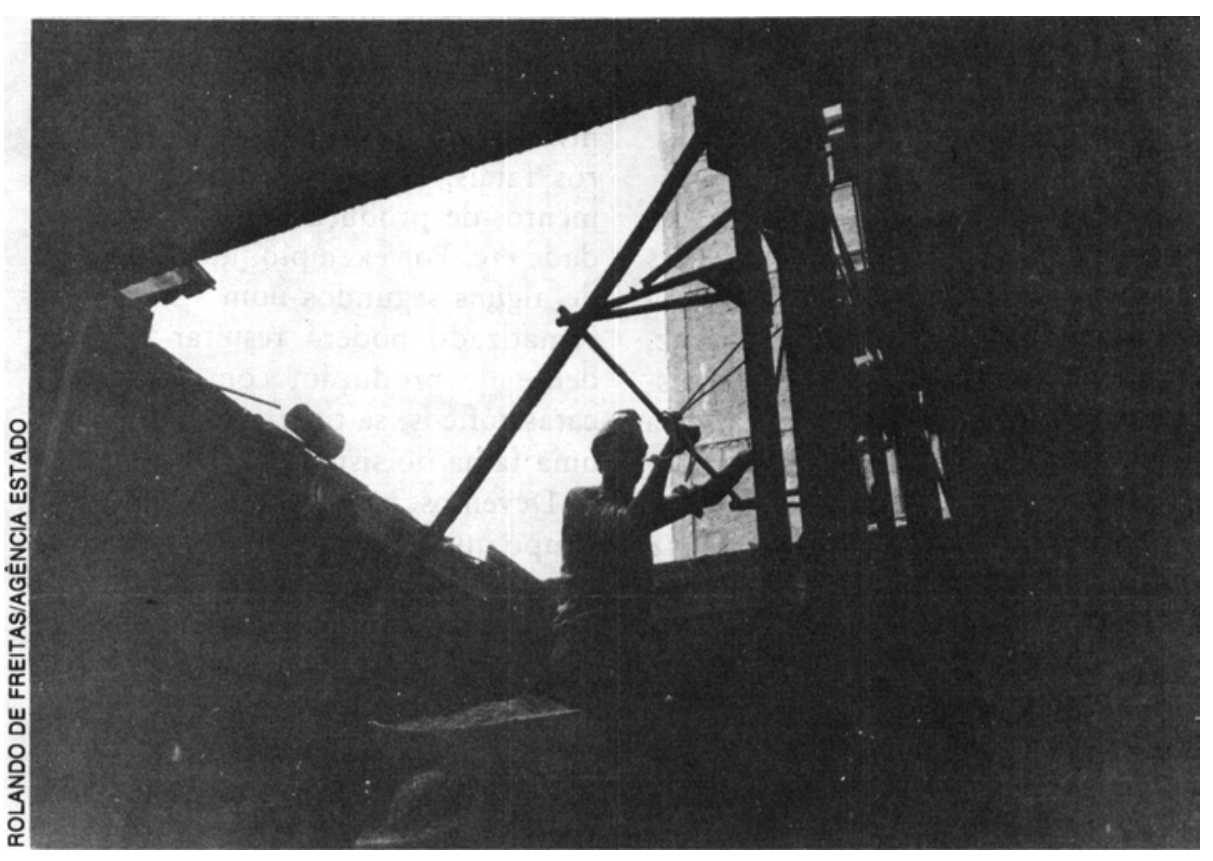

pesquisa em conjunto com os trabathadores porque devemos conhecer o processo de trabalho e, para tanto, devemos aprender como se dá esse processo a partir dos trabalhadores. Esta pesquisa foi realizada em curto espaço de tempo, porque eles tinham o interesse de levar os resultados obtidos para a mesa de negociação com a empresa e obter a redução de jornada de trabalho e aumento de folga.

A nossa pesquisa revelou que estes dois fatores estavam profundamente vinculados: tanto a jornada de 8 horas era excessiva quanto as folgas eram demasiado pequenas para repouso. Depois soubemos que a empresa também tinha encomendado uma outra pesquisa a um outro grupo de pesquisadores. Parece que o conjunto das duas pesquisas acabou favorecendo os trabalhadores. Eles não conseguiram a redução da jornada diária, mas conseguiram uma modificação na escala com menos períodos noturnos e também um aumento de folga. Agora, eles continuam batalhando pela redução da jornada que, com a nova Constituição, deverá ser obtida, acreditamos.

\section{Um assunto ocultado}

Sempre se deu muita importância aos aspectos relacionados ao desenvolvimento da personalidade, aos fatores genéticos, às influências da vida familiar, na gênese dos distúrbios psíquicos. Mas a influência das condiçōes de trabalho - especialmente da organização do trabalho - de modo geral permaneceu como tema evitado. Diria mesmo que o assunto foi ocultado por muito tempo, inclusive por empresas que realizaram pesquisas a respeito, mantendo secretos os resultados das mesmas, conforme revela uma importante revisão do assunto feita por Alan McLean. Então, conclui-se que, como o sofrimento mental relacionado ao trabalho é por ve. zes tảo evidente, há fortes interesses dirigidos contra uma ampliação do esclarecimento e da discussão sobre o assunto. No Brasil, obter registros referentes a diagnósticos psiquiátricos e de outras doenças, segundo tipo de ocupação profissional, é impraticável e tais registros nunca estảo disponiveis, seja nas empresas, scja nas instituiçōes oficiais que deveriam dispor de estatísticas a respeito.

Por outro lado, existe uma evidente barreira a que o público receba informaçōes a respeito dos efeitos de determinadas situações de trabalho sobre a saúde mental, sobre a qualidade de vida. Existem jornalistas interessados nessa questão, sensíveis aos aspectos sociais envolvidos nela; mas as matérias jornalísticas a esse respeito são vetadas. Isso ocorreu, por exemplo, muito recentemente, quando se tentou informar a opinião pública sobre como o trabalho em turnos de revezamento atinge a saúde, antes de acontecer a votação do assunto no segundo turno da Assem. 
bléia Constituinte. Foram produzidos artigos, informes, porém a publiççāo foi impedida por 'ordens superiores' dentro de grandes empresas jornalísticas.

Já nos Sindicatos, o assunto vem ganhando espaço gradualmente, pois lá estão voltados para a seríssima questão salarial que, por sua vez, também tem importantes repercussões para a saúde psicossocial e para a saúde geral. Assim, fica restando pouco espaço para a questão da saúde e, em particular, da saúde mental. Mas é uma batalha que está sendo levada adiante já, por vários Sindicatos e pelo DIESAT. E é impressionante a sensibilização que se observa a nivel dos próprios trabalhadores, em qualquer categoria profissional, quando o assunto é abordado. Quando se toca nessas questōes, eles reconhecem os problemas que sentem e vivem no seu cotidiano de trabalho e de vida.

No II Congresso dos Trabalhadores de Saúde Mental, em outubro de 1986 , houve muito interesse quando os trabalhadores de Saúde Mental discutiram as suas condições de trabalho: a agressão que sofrem sua própria saúde mental, trabalhando em instalaçōes precárias, com salário rebaixado e uma enorme demanda de pacientes.

\section{Jornada de trabalho - interesses patronais}

É importante informar e conscientizar os trabalhadores para que possam partir para uma negociação útil com os patrões. Acredito que as $\mathrm{em}$ presas modernas (no sentido autêntico desse adjetivo) vão se abrir no Brasil - como já se abriram as empresas na Europa - para considerar a importância da saúde mental no trabalho, tanto para os próprios trabalhadores quanto para a produção.

Acho que é necessário o psicólogo ter clareza sobre a argumentação que pode usar nesse momento do desenvolvimento tecnológico brasileiro. $\mathrm{O}$ cansaço mental e o tédio podem prejudicar não só a saúde, mas também o desempenho, conduzir a acidentes, falhas de $\mathrm{F}$ : Jdução, absenteísmo etc.

Vale lembrar que estamos num estágio tecnológico, no qual, de fato, o trabalho mental se torna muito importante para a qualidade da produ- ção. Se os limites mentais do trabalhador nâo forem respeitados, vamos ter conseqüências que irão pesar * nível financeiro. Poderão ocorrer erros fatais, com prejuízos de equipamento, de produção, de competitividade etc. Por exemplo, um "cochilo" de alguns segundos num sistema automatizado poderá resultar em acidente de produção, com resultados catastróficos, se tiver coincidido com uma falha do sistema.

Devemos passar a considerar o tempo que o trabalhador fica operando numa atividade tremendamente monótona, com uma grande sobrecarga quantitativa de exigência de atenção permanente. Somente quando algo estiver errado ele deverá tomar decisões que deverão ser imediatas e rápidas. Sabemos que, depois de algumas horas, em situação de monotonia, há uma diminuição da atividade do sistema nervoso central, com uma tendência à sonolência, havendo um conflito entre esta necessidade fisiológica e o esforço de se manter atento. Este conflito é muito penoso e quanto maior a jornada de trabalho, maior é o risco de ocorrer algum acjdente. Alguns empresários mais atentos já constataram que há vantagem em contratar um número maior de operadores para garantir que não haja grandes quebras de produção, bem como aumentar pausas e diversificar as atividades ao longo da jornada diária.

Considero muito interessante procurar estimular novos pesquisadores a adentrarem nessa questão da saúde mental do trabalhador. E uma questão muito ampla que abrange todas as formas de trabalho e todas as categorias profissionais. Junto com outras categorias profissionais, os psicólogos podem fazer reuniōes amplas para aprofundar este tema e área de atuaçào. Eu estive em Manaus, onde encontrei um grupo dedicado a este tema. No Rio de Janeiro, em Minas Gerais, na Bahia e em diversos outros Estados, os profissionais de Saúde começam a ficar interessados e reconhecem a importância desta área de pesquisa, de ensino e de atuação profissional.

\section{Uma questio preventiva}

Para que contribuem os resultados destes estudos? Através de sua divulgaçāo, suscitar reflexōes e discussōes, negociações e entendimentos que possam levar a mudanças favoráveis. E importante sensibilizar a sociedade como um todo, através de um movimento de opinião pública. É preciso alertar as pessoas para o fato de que o trabalho pode ser algo bom e realizador, mas também pode ser adoecedor. Como tem sido muito adoecedor no Brasil, é preciso reforçar este alerta.

A partir dos resultados destes estudos, não é simples poder instituir a prevenção. Esta nāo poderia ser estabelecida tecnocraticamente. Pela própria essência da problemática, ela supõe um nível de participação dos trabalhadores nos diversos níveis: junto com os pesquisadores, na negociação com os empresários etc. Tudo isso para que possam ser transformados aqueles aspectos que se revelaram adoecedores e que sejam decorrentes da organização do trabalho, dos equipamentos, ou de condições ambientais. Aliás, falei pouco nesta entrevista das questões ligadas ao ambiente e é preciso enfatizar que, junto aos trabalhadores industriais, encontramos condições como ruído constante, temperaturas elevadas, poeira, falta de ventilação, além de outras, como causas de mal-estar, irritabilidade e cansaço, contribuindo, portanto, para o desgaste psíquico e, ao mesmo tempo, físico dos trabalhadores.

Além da dimensão organizacional e ambiental, não se pode esquecer, dentro da questão preventiva, das condiçōes gerais de vida, ou melhor, do contex to social, econômico e político da vida dos trabalhadores, ao qual as condições de trabalho estão. vinculadas. A prevenção somente pode ser entendida em termos de transformação e libertação, abrangendo todos os níveis - desde o posto de trabalho até aspectos organizacionais e ambientais, política de pessoal da empresa e contexto mais amplo. Enfim, acho que a prevenção somente pode ser pensada de forma participativa, constituída como processo de mudança em que algumas medidas podem ser acionadas de forma mais imediata (como, por exemplo, a questão ambiental) e outras ao longo de uma luta continuada e consciente". 